\title{
Peningkatan Efektivitas Cooling Tower dengan Metoda Air High Speed
}

Sri Wuryanti ${ }^{1}$

${ }^{1}$ Jurusan Teknik Konversi Energi, Politeknik Negeri Bandung, Indonesia

email : sriwuryanti.lamda@gmail.com

\begin{abstract}
Abstrak
Cooling tower merupakan suatu alat yang berfungsi untuk menyerap panas pada fluida air yang berasal dari heat exhanger (kondensor, generator air cooler, lube air cooler, boiler feed pump) menggunakan fluida udara yang dialirkan secara natural maupun dialirkan oleh fan. Kalor panas yang diserap oleh udara membutuhkan kontak yang baik antara air dan udara agar terjadi proses pendinginan yang maksimal. Proses pendinginan yang maksimal pada prakteknya tidak bisa terjadi karena dipengaruhi oleh komponen yang terpasang pada cooling tower. Penelitian ini bertujuan untuk merancang efektifitas cooling tower dengan mode high speed. Pengamatan dilakukan pada cooling tower tipe induced draft cross flow. Teknologi Material membedakan material menjadi tiga bagian yakni material cair, material gas dan material padat, disini akan merancang penggunaan material gas ideal yakni udara sebagai salah satu fokus untuk peningkatan fektivitas cooling tower. Metode yang digunakan adalah mode high speed yaitu dengan menambah keceptan udara sehingga panas yang diserap oleh udara lebih banyak. Metode perhitungannya sendiri menggunakan metode pendekatan secara langsung dan tidak langsung. Perhitungan efektivitas dengan metode langsung menggunakan neraca massa dan energi dan secara tak langsung menggunakan perhitungan cara Range and Approac. Setelah menggunakan mode high speed dengan meningkatkan kecepatan angin menjadi $3 \mathrm{~m} / \mathrm{s}$ diharapkan dapat menaikkan efektivitas sebesar $27,7 \%$.
\end{abstract}

Kata Kunci : air, cooling tower, generator, kondensor, udara.

\section{PENDAHULUAN}

Kalor panas yang diserap oleh udara membutuhkan kontak yang baik antara air dan udara agar terjadi proses pendinginan yang maksimal. Proses pendinginan yang maksimal pada prakteknya tidak bisa terjadi karena dipengaruhi oleh komponen yang terpasang pada cooling tower seperti pipa, fan, fill, drift eliminator, pompa, blade, louver, dan lainnya [1-3].

Cara mengatasi masalah tersebut dengan melakukan perancangan peningkatan efektivitas cooling tower untuk mengetahui seberapa baik operasi cooling tower tersebut sedangkan selama ini belum dilakukan pengkajian peningkatan efektiviatas cooling tower dengan mode high speed.

Mode high speed adalah suatu cara peningkatan efektivitas dengan mnaikkan kecepatan udara dengan tujuan untuk terjadinya proses penyerapan panas yang lebih banyak

\section{TINJAUAN PUSTAKA}

\section{II.1 Metode Perhitungan Secara Langsung}

Perhitungan Neraca Massa dan Energi pada Cooling Tower dilakukan dengan asumsi: Operasi berada dalam keadaan steady state dan Daya konsumsi fan diabaikan [3-7].

Neraca energi didapatkan persamaan berikut:

$$
\begin{aligned}
& \quad\left(m_{w \text { in }} \times C_{p w} \times T_{w \text { in }}\right)-\left(m_{w \text { out }} \times C_{p w} \times T_{w \text { out }}\right) \\
& +\left(m_{a} \times\left(h_{a \text { out }}-h_{a \text { in }}\right)=0\right.
\end{aligned}
$$

Jumlah air yang terevaporasi adalah sebagai berikut, $m_{w e}=$ $m_{a}\left(w_{a \text { out }}-w_{a \text { in }}\right)$; biasanya diasumsikan sebesar $1 \%$ dari jumlah air yang masuk sehingga besarnya nilai $\left[\left(m_{a} \times\right.\right.$ $\left.\left(w_{a \text { out }} \times w_{a \text { in }}\right) \times C_{p w} \times T_{w \text { out }}\right]$ dapat diabaikan. Dengan demikian, persamaan dapat dituliskan kembali menjadi, $\left(m_{w \text { in }} \times C_{p w} \times T_{w \text { in }}\right)=\left(m_{a} \times\left(h_{a \text { out }}-h_{a \text { in }}\right)\right.$

Efektivitas suatu heat exchanger didapat dari perbandingan aktual pendinginan dan maksimum pendinginan.

$$
\begin{aligned}
& \varepsilon=\frac{\text { q aktual }}{q_{\text {max }}} \cdot \mathrm{X} 100 \% \\
& \varepsilon=\frac{\left[m_{a} \times\left(h_{\text {a out }}-h_{\text {ain }}\right)\right]+\left(m_{e v} \times h_{w}\right)}{m_{w \text { in }} \times C_{p w} \times T_{w i n}} \times 100 \%
\end{aligned}
$$

Tahapan dalam menghitung efektivitas

Tahap 1 Menentukan laju aliran air (m_w)

$m_{w}=Q_{w} \times \rho_{w}$

Tahap 2 Menentukan laju aliran udara (m_a)

$m_{a}=Q_{a} \times \rho_{a}$

$m_{a}=v_{a \text { out }} \times A_{\text {out }} \times \rho_{a}$

Tahap 3 Menentukan laju aliran air yang menguap $\left(m_{e v}\right)$

$m_{e v}=m_{a} \times\left(w_{a \text { out }}-w_{a \text { ih }}\right)$

Tahap 4 Perhitungan efektivitas

$\varepsilon=\frac{q_{\text {terima }}}{q_{\text {lepas }}} \times 100 \%$

$\varepsilon=\frac{\left[m_{a} \times\left(h_{a \text { out }}-h_{a \text { in }}\right)\right]+\left(m_{e v} \times h_{w}\right)}{m_{w} \times C_{p w} \times\left(T_{w i n}-T_{w o u t}\right)} \times 100 \%$

Data properties air dan udara dibutuhkan untuk menghitung efektivitas.

\section{II.2 Metode Perhitungan Secara Tak Langsung}

Kinerja cooling tower ditinjau dari range (R), approach (A), efektifitas termal $(\varepsilon)$, kapasitas pendinginan (q_C), kehilangan air akibat evaporasi (W_e), siklus kosentrasi (C.O.C), kehilangan air akibat terbawa oleh udara yang keluar fan (W_D), kehilangan air akibat pembuangan sejumlah air untuk mengontrol agar tidak terjadi peningkatan kandungan (W_B), make-up water (W_mu), dan rasio air-udara (L/G) [3]. Berikut penjelasan rumus yang digunakan:

a. Range (R) 
Range merupakan perbedaan temperatur air yang masuk (Tw in) dan air yang keluar ( $\mathrm{Tw}$ out). Nilai range yang tinggi menunjukkan bahwa cooling tower mampu menurunkan temperatur air dengan efektif.

$$
R\left({ }^{\circ} \mathrm{C}\right)=T_{w \text { in }}\left({ }^{\circ} \mathrm{C}\right)-T_{w \text { out }}\left({ }^{\circ} \mathrm{C}\right)
$$

b. Approach $(\mathrm{A})$

Approach merupakan perbedaan temperatur air yang keluar (Tw out) dan temperatur bola basah udara yang masuk (Twb in). Nilai approach yang semakin rendah menunjukkan bahwa semakin baik kinerja cooling tower.

$$
A\left({ }^{\circ} \mathrm{C}\right)=T_{w \text { out }}\left({ }^{\circ} \mathrm{C}\right)-T_{\text {wb in }}\left({ }^{\circ} \mathrm{C}\right)
$$

c. Efektifitas termal $(\varepsilon)$

Efektifitas termal merupakan rasio antara range dan range ideal atau dengan kata lain nilai range dibagi dengan nilai range dan approach. Nilai rasio yang semakin tinggi menunjukkan bahwa semakin tinggi efektifitas cooling tower.

$$
\varepsilon(\%)=\frac{\text { Range }\left({ }^{\circ} \mathrm{C}\right)}{\text { Range }\left({ }^{\circ} \mathrm{C}\right)+\text { Approach }\left({ }^{\circ} \mathrm{C}\right)} \times 100 \%
$$

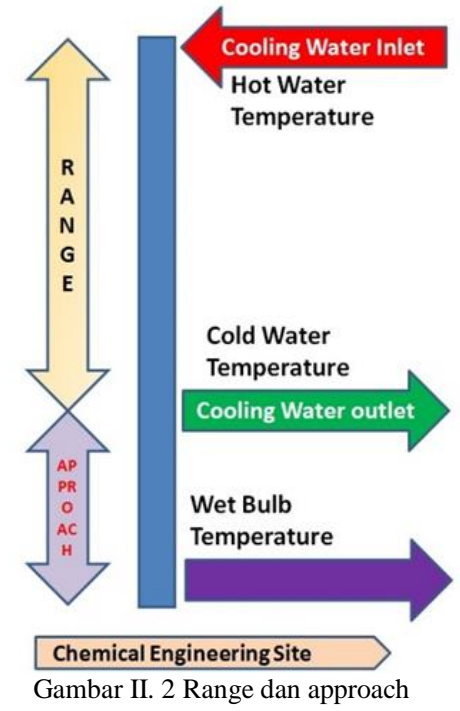

\section{METODA PENELITIAN}

Perancangan penetapan kecepatan udara adalah dengan memvariasikan kecepatan udara yakni

1. $1 \mathrm{~m} / \mathrm{s} ; 1,5 \mathrm{~m} / \mathrm{s}, 2 \mathrm{~m} / \mathrm{s} ; 3 \mathrm{~m} / \mathrm{s} ;$ dan $3,5 \mathrm{~m} / \mathrm{s}$

2. Melalukan perhitungan seperti pada persamaan $1 \mathrm{~s} / \mathrm{d} 11$.

3. Merekomendasikan bahwa efektivitas terbaik pada kecepatan udara yang optimal.

Penyelesaian perhitungan digambarkan seperti berikut.

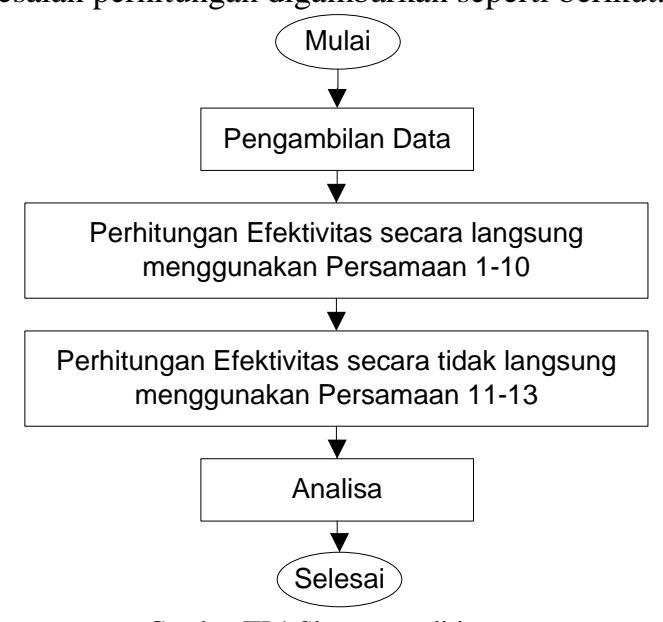

Gambar III.1 Skema penelitian

\section{HASIL DAN PEMBAHASAN}

Perhitungan efektivitas dilakukan menggunakan pendekatan langsung dengan neraca massa dan energi (NME) dan pendekatan tidak langsung dengan menggunakan Range-Approach. Perhitungan efektivitas dengan menggunakan NME membandingkan $\mathrm{q}_{\text {lepas }}$ dan $\mathrm{q}_{\text {terima }}$ pada fluida air maupun udara.

Pengambilan data menggunakan NME dibutuhkan parameter pengukuran diantaranya laju aliran air, temperatur air, temperatur udara, dan laju aliran udara.

Perhitungan efektivitas dengan Range-Approach merupakan metode pengkajian pendinginan aktual dengan pendinginan maksimum dimana $\mathrm{q}_{\mathrm{aktual}}=$ range, $\mathrm{q}_{\max }=$ range + approach . Parameter pengukuran yang dibutuhkan diantaranya temperatur air dan temperatur udara.

\section{IV.1 Analisa Secara Langsung Berdasarkan NME}

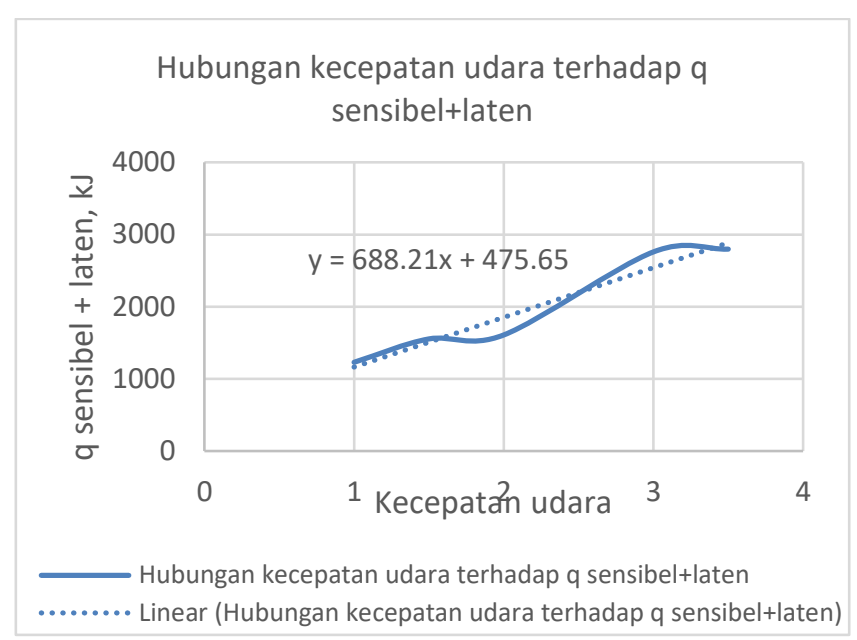

Gambar IV.1 Hubungan antara kecepatan udara terhadap q laten + sensible

Berdasarkan profil kalor pemanasan pada gambar IV.1 menunjukkan bahwa kalor pemanasan udara mencapai puncaknya pada kecepatan $3 \mathrm{~m} / \mathrm{s}$. Hal tersebut dipengaruhi oleh nilai kalor kelembapan, banyaknya massa udara yang mengalir, serta perbedaan temperatur bola kering udara yang masuk dengan temperatur bola kering udara yang keluar [8]. Semakin tinggi kecepatan udara maka nilai kalor yang dilepas oleh udara makin besar, selama variable lain mendekati konstan.

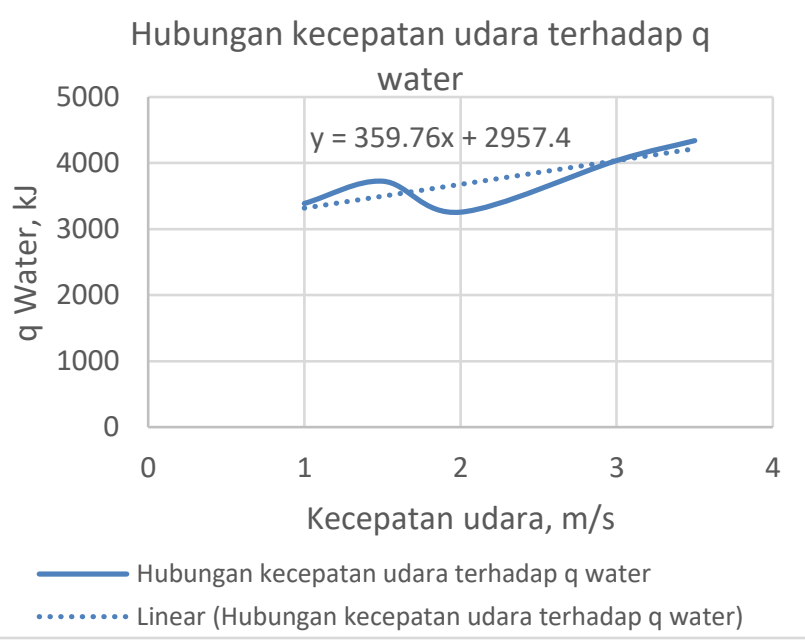

Gambar IV.2 Hubungan antara kecepatan udara terhadap q water 
Berdasarkan Gambar IV.2 menunjukkan kapasitas pendinginan berubah setiap saat. Kapasitas pendinginan dipengaruhi oleh laju air yang mengalir, kapasitas panas air, dan perbedaan temperatur air yang masuk dan yang keluar. Kenaikan kapasitas pendinginan mulai terjadi kecepatan udara $1,5 \mathrm{~m} / \mathrm{s}$, kemudian mengalami penurunan, dan naik lagi mlai pada kecepatan $3 \mathrm{~m} / \mathrm{s}$ sampai puncaknya yakni 3,5 m/s. Hal tersebut terjadi karena debit air yang semakin mengalir bertambah besar. Kapasitas pendinginan yang semakin besar menunjukkan bahwa semakin besar kalor yang dilepas oleh air [9].

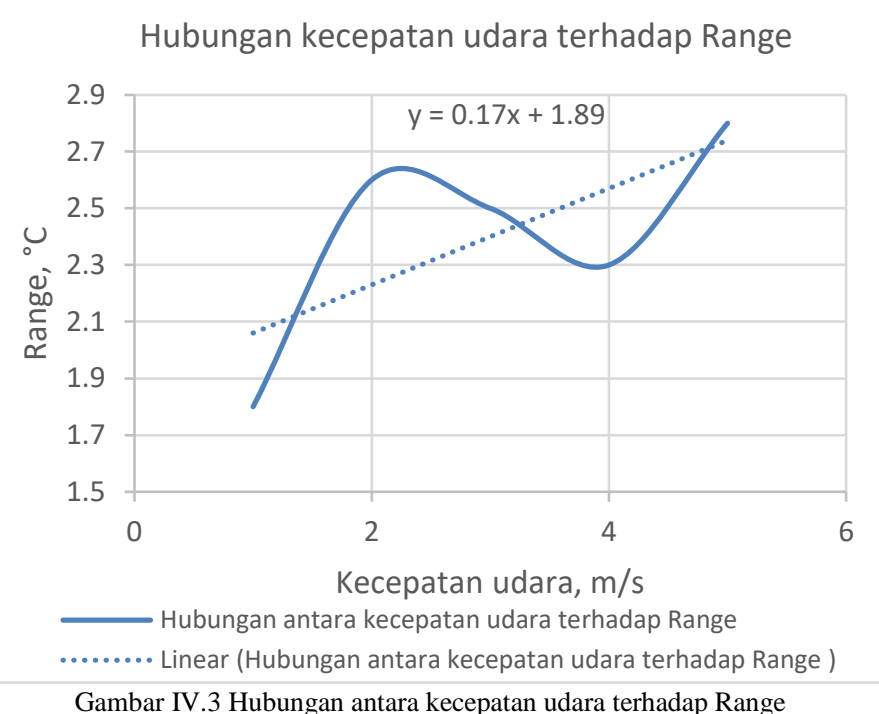

Gambar IV.3 menunjukkan bahwa kenaikan dan penurunan range dipengaruhi oleh temperatur air yang masuk $\left(\mathrm{T}_{\mathrm{w}}\right.$ in $)$ dan air yang keluar $\left(\mathrm{T}_{\mathrm{w} \text { out }}\right)$ pada cooling tower. Semakin besar perbedaan temperatur air yang masuk dan temperatur air yang keluar maka nilai range akan semakin besar. Range tersebut menunjukkan kemampuan cooling tower dalam menurunkan temperatur air sehingga jika range semakin tinggi maka kinerja cooling tower semakin bagus [10].

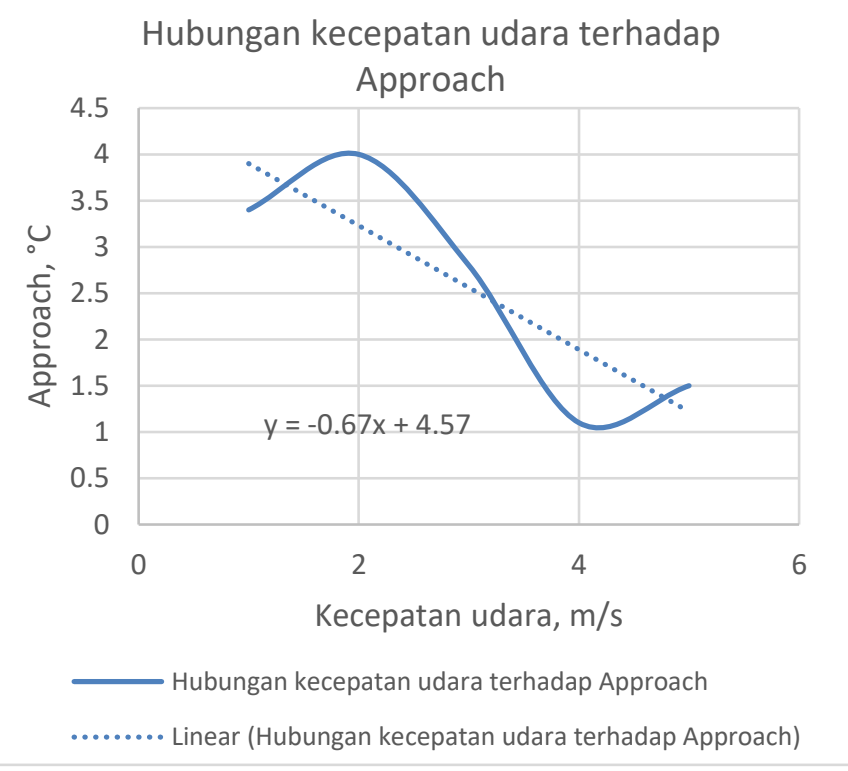

Gambar IV.4 Hubungan antara kecepatan udara terhadap Approach

Gambar IV.4 menunjukkan bahwa semakin besar nilai keepatan udara, maka semakin keil nilai approach. Hal tersebut terjadi karena dipengaruhi oleh temperatur air yang keluar $\left(\mathrm{T}_{\mathrm{w} \text { out }}\right)$ dan temperatur bola basah udara yang masuk $\left(\mathrm{T}_{\mathrm{wb}}\right.$ in $)$. Approach didapatkan dari hasil pengukuran temperatur air yang masuk $\left(\mathrm{T}_{\mathrm{w}}\right.$ in $)$ dan temperatur bola basah udara yang masuk ( $\mathrm{T}_{\mathrm{wb}}$ in $)$. Approach yang semakin kecil menunjukkan kinerja cooling tower yang semakin baik karena temperatur air yang keluar mendekati nilai temperatur bola basah yang masuk [11].

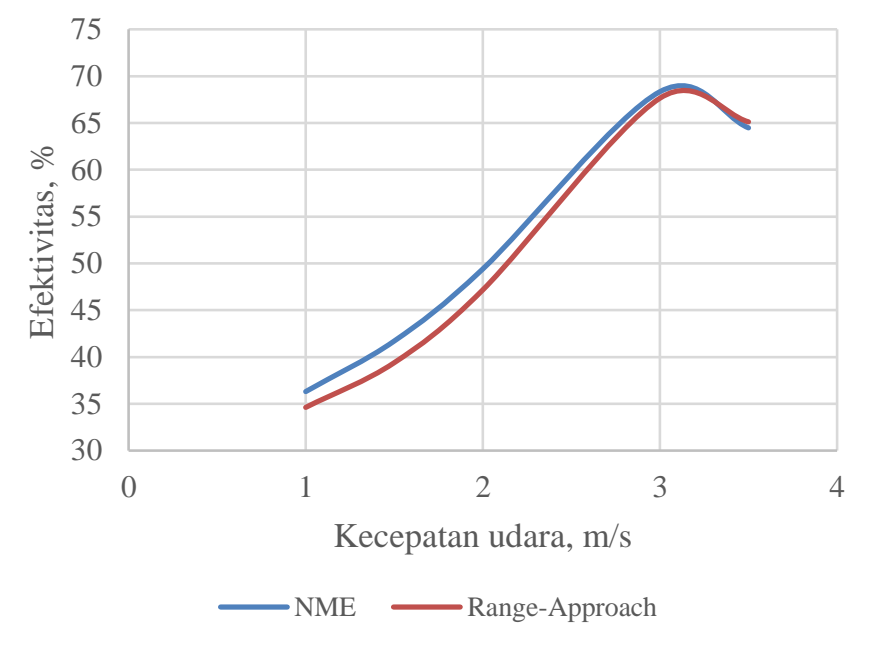

Gambar IV.5 Perbandingan Efektivitas Secara NME terhadap Range-Approach

Efektivitas berdasarkan NME dipengaruhi oleh besarnya q aktual yaitu besarnya panas sensibel yang dilepas air dan $\mathrm{q}$ max yaitu besarnya panas sensibel yang diterima oleh udara, serta panas laten yang terjadi akibat evaporasi air untuk mendinginkan air. Efektivitas berdasrkan Range dan approah pada dasarnya memiliki turunan persamaan dari NME dengan asumsi yang ditambahkan bahwa besarnya persentase air yang hilang pada cooling tower relatif kecil sehingga massa air yang keluar dianggap sama dengan massa air yang masuk sehingga didapatkan bahwa qaktual merupakan perbedaan temperatur air yang masuk dan temperatur air yang keluar (range) [12]. Massa udara yang masuk dianggap sama dengan massa udara yang keluar sehingga q max merupakan range ditambah perbedaan temperatur air yang keluar dengan temperatur bola basah udara yang masuk (approach).

\section{KESIMPULAN}

Analisa Cooling Tower berdasarkan perhitungan NME dan Range-Approacch dengan metode Air High Speed didapatkan bahwa peluang peningkatan efektivitas cooling tower dapat dilakukan pada Kecepatan angin $3 \mathrm{~m} / \mathrm{s}$ sehingga menghasilkan efektivitas $68.34 \%$ (berdasarkan perhitungan NME) dan $67.65 \%$ (berdasarkan Range-Approach). Kedua metode berbeda hasil sekitar $1 \%$.

\section{DAFTAR PUSTAKA}

[1] ASHRAE Handbook. 2004. HVAC Systems and Equipment

[2] Michael J. Moran. 2014. Fundamental of Thermodynamic Engineering, Daver:Wiley.

[3] Perry, H. Robert. 2006. Chemical Engineering Handbook. 7th ed., United State of America, Mc Graw Hill

[4] Calautit, J. K., Hughes, B. R., Chaudhry, H. N., \& Ghani, S. A. 2013. CFD analysis of a heat transfer device integrated wind tower system for hot and dry climate. Applied Energy, 112, 576-591.

[5] Mkhokheli Ndlovu and Thokozani Maozi. 2014. Design and Optimisation of Power Plant Utility Systems, Computer Aided Chemical Engineering 34:567-572

[6] Francesco Babicha, Malcolm Cooka, Jan Cremersb and George Papachristoua. 2017. The impact of ventilation cooling towers on plus energy houses in southern Europe, International Journal of Ventilation, 
Vol. 16, No. 4, 323-344

[7] Xiaoqing Wei,Nianping Li , Jinqing Peng, Jianlin Cheng,Jinhua Hu andMeng Wang. 2017. Performance Analyses of Counter-Flow Closed Wet Cooling Towers Based on a Simplified Calculation Method, Energies10, 282, 1-15

[8] Faraz Afshari and Heydar Dehghanpour. 2018. A Review Study On Cooling Towers; Types, Performance and Application, International Conference on Nuclear Structure Properties (NSP2018), TrabzonTURKEY, 12-14 September 2018

[9] E Novianarenti, G Setyono and A G Safitra.2019. Experimental Study of The Performance Characteristic an Induced Draft Cooling Tower with Variates Fillings, The 1st International Conference on Advanced Engineering and Technology IOP Conf. Series: Materials Science and Engineering 462.

[10]Habibur Rahman, Altab Hossain, and Mohammad Ali. 2019. Experimental analysis on heat transfer performance of cooling tower with nanofluid, AIP Conference Proceedings 2121, 070011 .

[11]Detlev G. Kroger. 2004. Air cooled heat exchanger and cooling tower termal flow performance evaluation and design. Oklahoma: Penwell Coorperation.

[12] Bureau of Energy Efficiency, Ministry of Power, India 2004. Cooling Tower. In Energy Efficiency in Electrical Utilities. Chapter 7. 